\title{
Patient Satisfaction with the Emergency Department Experience in the Era of COVID-19: A National Survey
}

\author{
Khadijah Banjar and Sharafaldeen Bin Nafisah
}

\begin{abstract}
Background: Patient satisfaction with an ED visit is often overlooked during the ongoing COVID-19 pandemic, and requires further examination. Aim: We aim to investigate, on a national scale, patients' satisfaction during their ED encounter, and to explore the determinants of such satisfaction. Methods: This is a cross-sectional analysis conducted between January and February 2021 throughout Saudi Arabia. Result: The total number of patients was 508. The median satisfaction score for the clarity of information provided in the ED was 40 $(\mathrm{SD}=4.94)$, while satisfaction with the relationship with staff and $E D$ routine revealed a median score of $39.9(\mathrm{SD}=5.08)$. We noted several determinants of ED satisfaction, including age, marital status, educational status, clarity of the treatment plan, improvement of their condition while in the ED, verbal and/or written discharge instructions, as well as a follow-up call two days after discharge. Conclusion: Patient satisfaction is an integral part of the patient-centred approach in the ED, and should be continuously evaluated.
\end{abstract}

Index Terms-Patient satisfaction, emergency department satisfaction, satisfaction determinants.

\section{INTRODUCTION}

While the healthcare sector struggles to overcome the COVID-19 pandemic, satisfaction with an emergency department visit is often overlooked - in the ED, provision of timely management often comes at the expense of patientcentredness. However, knowledge of patients' perception of the experience is imperative, not only as a key performance indicator, but also for the integrity of emergency medicine practice.

Patients are generally satisfied when their expectations are met [1], [2]. When a patient had their condition clearly explained to them, satisfaction appeared to increase [2], [3]. Moreover, involving the patient in decisions relating their health also correlated with satisfaction, especially among those with chronic diseases [4], [5]. Even the manner in which staff interacted with patients was an important determinant of their satisfaction [3], [5], [6]. Hence, it should not be assumed that a patient seeking treatment will be satisfied solely upon the provision of such treatment; rather, their satisfaction encompasses every aspect of the patient's experience during such a visit.

Expectations of an ED encounter differ from patient to patient, as well as varying among different cultures. In Saudi

Khadijah Banjar, Sharafaldeen Bin Nafisah are with Emergency Department, King Fahad Medical City, Riyadh, Saudi Arabia., e-mail: khadeejahbanjar@hotmail.com, e-mail: sbinnafisah@kfmc.med.sa

Khadijah Banjar is the corresponding author.
Arabia, there is a lack of generalisable studies exploring satisfaction with an ED visit [7]; here, we aim to investigate patient satisfaction with ED encounters on a national scale. We also aim to investigate the sociodemographic determinants of satisfaction, and to explore the effect on satisfaction of an improvement in their condition while in the ED. We also aim to explore perceptions of the clarity of treatment plans and the method of discharge instructions, and whether there is a role for a follow-up call two days after discharge.

\section{METHODS}

This is a cross-sectional analysis conducted between January and February 2021 throughout Saudi Arabia. We estimated a sample size of 385 using the Raosoft $\mathbb{R}$ calculator, based on Saudi Arabia's population of $34000000(0.05$ significance level, $5 \%$ margin of error and $95 \%$ confidence level) and expected response distribution 50\%.

Using an online survey tool, we applied the validated Arabic version of Echelle de Qualité des Soins en Hospitalisation (EQS-H) [8]. This survey aims to measure satisfaction with the healthcare encounter in general, although we tailored our questions to emergency department visits. The survey measures satisfaction in two main areas: clarity of information, and the relationship with staff and ED routine.

In order to avoid the ceiling effect [9], responses were categorised as 'Positive' or 'Negative', wherein 'Poor' and 'Average' were negative, and 'Good', 'Very good', and 'Excellent' were positive. The inclusion criteria were: any patient who had visited an emergency department in any Saudi Arabian province. Only incomplete responses were excluded. We used the SPSS software, version 21, for analysis, and the STROBE guidelines for reporting [10]. The study complied with and was approved by the Research and Ethics Committee.

\section{RESULTS}

\section{Demographics:}

The total number of patients was 508. The participants' demographic details are illustrated in Table 1.

\section{Satisfaction scores:}

Out of a score of 50, the median satisfaction score for the clarity of information provided in the ED was $40(\mathrm{SD}=4.94)$, while satisfaction with the relationship with staff and ED routine revealed a median score of $39.9(\mathrm{SD}=5.08)$. The total satisfaction over both areas is $79.9 \%$; an analysis of positive 
and negative response scores for each question is illustrated in Table 2.

\section{The Saudi Arabian provinces:}

We noted a difference in total satisfaction scores among the different Saudi provinces. An inspection of the mean ranks reveals higher satisfaction in the southern province $(M=283.34)$, followed by the northern province $(M=274.26)$, eastern province $(M=251.17)$, central province $(M=244.39)$ and, lastly, the western province $(\mathrm{M}=229.84)$; Kruskal-Wallis test $(4)=11.773, p<0.05$. Although a difference was noted on each domain, the difference was not significant between provinces, $\mathrm{p}>0.05$.

\section{Determinants of ED satisfaction:}

I. Age: A negative correlation was noted between age and total satisfaction score; $\mathrm{r}=-0.12, \mathrm{n}=507, \mathrm{p}<0.05$. Linear regression uncovered a significant regression equation: $[F(1,505)=7.36, p<0.05]$ with an $R^{2}$ of 0.014 . Specifically, there is a negative correlation between participants' age and their perception of the clarity of the information provide; $r=-$ $0.108, \mathrm{n}=507, \mathrm{p}<0.05$. Linear regression was also calculated, and a significant regression equation was found: $[F(1,505)=5.95, p<0.05]$ with an $R^{2}$ of 0.012 . The effect of age on satisfaction with the relationship with staff and ED routine was also negative: $\mathrm{r}=-0.12, \mathrm{n}=507, \mathrm{p}<0.05$; the regression equation was $[F(1,505)=6.73, p<0.05]$ with an $R^{2}$ of 0.013 .

\section{GENDER: THERE WAS NO CORRELATION BETWEEN GENDER AND ANY OF THE SATISFACTION COMPONENTS; $\mathrm{P}>0 ; 05$}

III. Marital Status: Married participants reported a lower total satisfaction score $(M=73.89, \mathrm{SD}=10.34)$ than their unmarried counterparts $(\mathrm{M}=76.1, \mathrm{SD}=8.01), \mathrm{t}(477,86)=2.69, \mathrm{p}<0.05$. They also reported lower satisfaction with the clarity of information provided in the $\mathrm{ED}(\mathrm{M}=37, \mathrm{SD}=5.44)$ than unmarried participants $(\mathrm{M}=38.15, \mathrm{SD}=4.33), \mathrm{t}(483.26)=2.52, \mathrm{p}<0.05$. Likewise, satisfaction with the relationship with staff and ED routine in married participants was lower: $(\mathrm{M}=36.84$, $\mathrm{SD}=5.71)$ vs $(\mathrm{M}=37.95, \mathrm{SD}=4.29), \mathrm{t}(471.32)=2.53, \mathrm{p}<0.05$.

IV. Level of education: An inspection of the mean ranks suggests that the higher their educational level, the less satisfied participants were with the clarity of information provided in the ED; Kruskal-Wallis test $(4)=25.45, p<0.05$. The same was true for their satisfaction with the relationship with staff and ED routine; Kruskal-Wallis test $(4)=30.74, p<0.05$, and their total satisfaction score; Kruskal-Wallis test $(4)=27.73, p<0.05$. This is illustrated in Table 3.

V. Presence of chronic diseases: The presence of chronic diseases did not positively or negatively affect the satisfaction score, $\mathrm{p}>0.05$.

VI. Clarity of the treatment plan: The overall percentage of participants who reported having a clear treatment plan was $74 \%(n=376)$. This segment reported a higher total satisfaction level $(\mathrm{M}=77.94, \mathrm{SD}=5.02)$ than those who did not report their treatment plan to be clear $(\mathrm{M}=66.58$, $\mathrm{SD}=12.92), \mathrm{t}(145.13)=9.846, \mathrm{p}<0.05$. They also exhibited a higher satisfaction score in both of these components when the components were investigated independently $\mathrm{t}(506)=11.57$, and $\mathrm{t}(144.03)=9.773, \mathrm{p}<0.05$.
However, there was a significant difference among the provinces in the number of participants who reported receiving a clear treatment plan. When we examined the negative perceptions in relation to this component, we noted that the western province had the highest negative perception at $34.1 \%(n=45)$, followed by the eastern province at $18.9 \%(\mathrm{n}=25)$, and the northern and central provinces at $17.4 \%(\mathrm{n}=23)$. The southern province reported the lowest negative perception towards the clarity of treatment plan, at $12.1 \%(n=16) ; X^{2}(4)=15.02$, $\mathrm{p}<0.05$.

Furthermore, perception of the clarity of the treatment plan differed between married and unmarried individuals; $\mathrm{X}^{2}(1)=6.65, \mathrm{p}<0.05$. Married individuals were less likely to report having a clear treatment plan $[59.8 \%(\mathrm{n}=79)$ vs $40.2 \%$ $(\mathrm{n}=53)]$.

VII. Improvement of condition while in the ED: $39.2 \%$ $(n=199)$ of participants reported improvement while in the ED. A major improvement was reported by $24.2 \%(n=123)$, whereas $29.3 \%(n=149)$ reported no improvement. Improvement during the ED stay was positively associated with satisfaction; Kruskal-Wallis test $(2)=142.56, p<0.05$, as illustrated in Table 4. It was also associated with higher satisfaction with the clarity of information provided in the ED; Kruskal-Wallis test $(2)=85.79, p<0.05$, and satisfaction with the relationship with staff and ED routine; Kruskal-Wallis test $(2)=135.18$, $\mathrm{p}<0.05$.

The percentage of participants reporting lack of improvement was highest in the western province at $34.2 \%(\mathrm{n}=51)$, followed by the central province at $24.5 \%(\mathrm{n}=37)$, eastern province at $16.8 \%(\mathrm{n}=25)$, northern province $15.4 \%(\mathrm{n}=23)$, and lastly the southern province at $8.7 \%(\mathrm{n}=13)$. It is interesting to note that the numbers reporting (fairly) high improvement were higher in the southern province at $44.7 \%$ $(\mathrm{n}=55)$, followed by northern province at $33.3 \%(\mathrm{n}=41)$, central province at $8.1 \%(\mathrm{n}=10)$, eastern province at $7.3 \%(\mathrm{n}=9)$, and lastly the western province at $6.5 \%(\mathrm{n}=8) ; \mathrm{X}^{2}(12)=40.53$, $\mathrm{p}<0.05$.

VIII. Method of discharge instructions: The majority of participants, $52.3 \%(\mathrm{n}=263)$, chose verbal instruction as their preferred method of discharge instructions, whereas $29.2 \%$ $(n=147)$ chose verbal and written. Written instruction alone was less preferred than the other options, at $11.1 \%(n=56)$. We noted that satisfaction with clarity of information provided in the ED scored higher in those who preferred verbal discharge instructions; Kruskal-Wallis test $(3)=10.968, \mathrm{p}<0.05$. This was also noted in the satisfaction with the relationship with staff and ED routine [Kruskal-Wallis test $(3)=14.907,(\mathrm{p}<0.05)$ ], as well as the total satisfaction score [Kruskal-Wallis test (3) $=18.327,(\mathrm{p}<0.05)]$. This is illustrated in Table 5.

The method of discharge instructions was not scored differently between males and females or between married and unmarried participants; $p>0.05$. However, the preference differed among the provinces; $X^{2}(12)=68.27, p<0.05$. The northern and southern provinces favoured the verbal method, at $28.1 \%$ $(\mathrm{n}=74)$ and $25.1 \%(\mathrm{n}=66)$ respectively. There is a preference for written instructions in the central and western provinces; $26.8 \%(\mathrm{n}=15)$ and $28.6 \%(\mathrm{n}=16)$ respectively. These provinces also reported a preference for verbal and written instructions, 
at $27.2 \%(\mathrm{n}=40)$ and $32 \%(\mathrm{n}=47)$ respectively, as did the eastern province, at $21.8 \%(\mathrm{n}=32)$.

IX. Follow-up call two days after discharge: $94.3 \%$ of participants preferred a follow-up call two days after discharge $(n=479)$. Those who reported high satisfaction with their relationship with staff were less likely to perceive the need for a follow-up call, $(\mathrm{M}=38.75, \mathrm{SD}=3.26)$ vs $(\mathrm{M}=37.31, \mathrm{SD}=5.16)$; $\mathrm{t}(37.1)=-2.204, \mathrm{p}<0.05$.

The preference for a follow-up call did not differ among provinces or between genders, $\mathrm{p}>0.05$. However, there was a difference in scores between married and unmarried participants, where unmarried participants were reluctant to have follow-up communication; $31 \%(\mathrm{n}=9)$ vs $69 \%(\mathrm{n}=20)$; $\mathrm{X}^{2}(1)=4.52, \mathrm{p}<0.05$.

\section{DISCUSSION}

This study uncovers a high overall satisfaction score for ED visits during the COVID-19 pandemic, with a comparable score reported for the clarity of information provided and the relationship with staff and ED routines. Due to the lack of benchmark statistics, it is not known whether or not these scores are affected by the constraints of the COVID-19 pandemic.

A sociodemographic analysis suggests that age is an essential determinant in our population. The elderly require more time for the explanation of their health, illness and risks; this should improve their satisfaction score. Moreover, married participants reported lower satisfaction with the clarity of information provided and the relationship with staff and ED routine, as well as a lower total satisfaction score. On the whole, this might be because they were less likely to receive a clear treatment plan; this could be explained by the healthcare provider's tendency to explain the plan to a close family member who often accompanies the patient, rather than directly to the patient. This approach is often justified when the family member requests that they (the family member) explain the diagnosis and treatment options to the patient. This social dilemma could perhaps be better addressed by asking the patient whether they would like the healthcare provider to explain to their caregiver/family member, and then to act accordingly.

It is prudent to involve the patient in the treatment plan, however, as this has a positive association with overall satisfaction with the ED visit, satisfaction with the clarity of information provided, and the relationship with staff and ED routine. This should be emphasised in the western province, as those participants had more negative perceptions with regard to this component.

In this analysis, we noted a high negative scores on explaining the possible side effects of the treatment, symptoms to look out for in the future, and activities that can be resumed after discharge (job, sport, etc.). This is an integral part of emergency medicine practice, and was shown to be positively associated with satisfaction in the ED setting [11]. To standardise care, it would be preferable to have a more standardised method of conveying the instructions, including basic information about the illness, and the date and time of the follow-up appointment. Furthermore, an emergency medicine provider also needs to explain to the patient that some illnesses do not improve instantly, and that the body requires time to heal - this should overcome the expectation of full recovery during the short ED stay. Nonetheless, keeping the patient in the ED for observation is justified, as even a slight improvement will improve their satisfaction score.

The concept of an emergency department follow-up is not new. It has been advocated as a mitigation strategy for emergency revisits [12], although, in another study, it failed to benefit the elderly [13]. However, there is a lack of protocolised practice, and a follow-up call is perhaps an unfamiliar concept to non-clinic-based practice. Given that $94.3 \%$ supported such follow-up, and that it is associated with a high overall satisfaction score, in this analysis we urge emergency department personnel to incorporate a follow-up call as part of the daily practice two days after discharge. Further analysis should be carried out regarding the effect of follow-up calls on emergency department revisits.

The limitations of this study are that two thirds of the participants were female, and the majority did not have a chronic disease.

\section{CONCLUSION}

Overall, we urge the application of personalised medicine for emergency department patients, in which it is that patient's pneumonia (for example) that is being treated, and not any other pneumonia. The expectations, the disease course, and the medication side effects need to be conveyed to an extent that satisfies the patient. Furthermore, we argue for the implementation of a follow-up call to improve satisfaction with the emergency department visit.

\section{REFERENCES}

[1] Crossing the Quality Chasm: A New Health System for the 21st Century. Washington (DC; US: National Academies Press, 2001.

[2] J. L. Jackson, J. Chamberlin, and K. Kroenke, "Predictors of patient satisfaction," Social Science \& Medicine, vol. 52, no. 4, pp. 609620, 2001. [Online]. Available: 10.1016/s0277-9536(00)00164-7;https: //dx.doi.org/10.1016/s0277-9536(00)00164-7

[3] T. Schoenfelder, J. Klewer, and J. Kugler, "Determinants of patient satisfaction: a study among 39 hospitals in an in-patient setting in Germany," International Journal for Quality in Health Care, vol. 23, no. 5, pp. 503-509, 2011. [Online]. Available: 10.1093/intqhe/mzr038;https://dx.doi.org/10.1093/intqhe/mzr038

[4] V.S. Fan, G. E. Reiber, P. Diehr, M. Burman, M. B. McDonell, and S. D. Fihn, "Functional status and patient satisfaction a comparison of ischemic heart disease, obstructive lung disease, and diabetes mellitus," Journal of General Internal Medicine, vol. 20, no. 5, pp. 452-459, 2005. [Online]. Available: 10.1111/j.1525-1497.2005.40057.x;https: //dx.doi.org/10.1111/j.1525-1497.2005.40057.x

[5] F. E. B. Setyawan, S. Supriyanto, Ernawaty, and R. Lestari, "Understanding patient satisfaction and loyalty in public and private primary health care," Journal of Public Health Research, vol. 9, no. 2, pp. $7376485-7376485$, 2020. [Online]. Available: 10.4081/jphr.2020. 1823;https://dx.doi.org/10.4081/jphr.2020.1823

[6] K. Otani, B. Waterman, K. M. Faulkner, S. Boslaugh, T. E. Burroughs, and C. W. Dunagan, "Patient Satisfaction: Focusing on "Excellent"," Journal of Healthcare Management, vol. 54, no. 2, pp. 93-102, 2009. [Online]. Available: 10.1097/00115514-200903000-00005; https: //dx.doi.org/10.1097/00115514-200903000-00005 
TABLE I

1. Demographic Details of the Participants.

\begin{tabular}{ll}
\hline $\begin{array}{l}\text { DEMOGRAPHICS } \\
\text { Age }\end{array}$ & PERCENTAGE \% (n) \\
25 years old and younger & $36.6(184)$ \\
25-35 years of age & $35.5(180)$ \\
35-45 years of age & $13.8(70)$ \\
45-55 years of age & $9.7(49)$ \\
55-65 years of age & $3.9(20)$ \\
More than 65 years of age & $0.8(4)$ \\
Gender & \\
Male & $36.8(187)$ \\
Female & $63.2(321)$ \\
Marital status & \\
Married & $50.2(255)$ \\
Unmarried & $49.8(253)$ \\
Chronic diseases & \\
Yes & $22.7(115)$ \\
No & $77.3(392)$ \\
Education & \\
Less than high school & $5.7(29)$ \\
High school & $30.7(156)$ \\
Diploma & $8.5(43)$ \\
Bachelor & $47(239)$ \\
Master and Higher & $8.1(41)$ \\
Area & \\
Central & $23.6(120)$ \\
Western & $24.4(124)$ \\
Eastern & $14.6(74)$ \\
Northern & $20.9(106)$ \\
Southern & $16.5(84)$ \\
\hline &
\end{tabular}

TABLE II

POSITIVE AND NEGATIVE RESPONSES RELATING TO EACH COMPONENT OF THE SATISFACTION SCORE.

\begin{tabular}{llc}
\hline Scale & Negative \% (n) & Positive \% (n) \\
How clear were the explanations & $11.8(60)$ & $88.2(448)$ \\
About my symptoms & $11.4(58)$ & $88.6(450)$ \\
About why I needed certain examinations or tests & $8.1(41)$ & $91.9(467)$ \\
About the results of my examinations or tests & $8.9(45)$ & $91.1(463)$ \\
About the aims of my treatment (medication, operation, etc.) & $19.9(101)$ & $80.1(407)$ \\
About possible side effects of my treatment & $12.2(62)$ & $87.8(446)$ \\
The hospital staff and the ward; How satisfied were you with the following? & $7.7(39)$ & $92.3(469)$ \\
The information as to which doctor was in charge of me & $12.4(63)$ & $87.6(445)$ \\
Efforts to ensure my privacy & $7.7(39)$ & $92.3(469)$ \\
Assistance given me for day-to-day activities (eating, dressing etc.) & $15.7(80)$ & $84.3(428)$ \\
Assistance for pain relief & $13.8(70)$ & $86.2(438)$ \\
The promptness of nurses in coming when called & $11.4(58)$ & $88.6(450)$ \\
The organisation of the ward & $13.6(69)$ & $86.4(439)$ \\
The atmosphere in the ward & $19.1(97)$ & $80.9(411)$ \\
The readiness of nurses to spend time with me & $17.9(91)$ & $82.1(417)$ \\
Information given to me when leaving the hospital; How clear were the explanations? & $88.2(448)$ \\
About the symptoms, I should watch for in the future & $11.8(60)$ & \\
About the activities I could resume after discharge (job, sport, etc.) & & $87.6(445)$ \\
about my medical care after discharge & $12.4(63)$ & $89.4(454)$ \\
Your overall opinion & & \\
I had as much say as I wanted in medical decisions that concerned me & $10.6(54)$ & \\
On the whole, the care and treatment that I received were. .. & & \\
\hline
\end{tabular}

[7] M. A. Abolfotouh, M. H. Al-Assiri, R. T. Alshahrani, Z. M. Almutairi, R. A. Hijazi, and A. S. Alaskar, "Predictors of patient satisfaction in an emergency care centre in central Saudi Arabia: a prospective study," Emergency Medicine Journal, vol. 34, no. 1, pp. 27 33, 2017. [Online]. Available: 10.1136/emermed-2015-204954;https: //dx.doi.org/10.1136/emermed-2015-204954

[8] G. Soufi, J. Belayachi, S. Himmich, S. Ahid, M. Soufi, A. Zekraoui, and R. Abouqal, "Patient satisfaction in an acute medicine department in Morocco," BMC Health Services Research, vol. 10, no. 1, pp. 149149, 2010. [Online]. Available: 10.1186/1472-6963-10-149;https: //dx.doi.org/10.1186/1472-6963-10-149

[9] L. Moret, J.-M. Nguyen, N. Pillet, B. Falissard, P. Lombrail, and I. Gasquet, "Improvement of psychometric properties of a scale measuring inpatient satisfaction with care: a better response rate and a reduction of the ceiling effect," BMC Health Services Research, vol. 7, no. 1, pp. 2225 402-2225 402, 2007. [Online]. Available: 10.1186/1472-6963-7-197;https://dx.doi.org/10.1186/1472-6963-7-197

[10] E. von Elm, D. G. Altman, M. Egger, S. J. Pocock, P. C. Gøtzsche, and J. P. V. and, "The Strengthening the Reporting of Observational Studies in Epidemiology (STROBE) Statement: Guidelines for Reporting Observational Studies," PLoS Medicine, vol. 4, no. 10, pp. e296e296, 2007. [Online]. Available: 10.1371/journal.pmed.0040296; https: //dx.doi.org/10.1371/journal.pmed.0040296

[11] L. Stevens, M. Fry, M. Browne, and A. Barnes, "Fast track patients' satisfaction, compliance and confidence with emergency department discharge planning," Australasian Emergency Care, vol. 22, no. 2, pp. 87-91, 2019. [Online]. Available: 10.1016/j.auec.2019.01.004;https: //dx.doi.org/10.1016/j.auec.2019.01.004 
TABLE III

THE MEAN DIFFERENCEIN SATISFACTION SCORE IN RELATION TO THE EDUCATIONAL LEVEL.

\begin{tabular}{lc}
\hline Educational level & Mean (n) \\
The satisfaction score with the clarity of \\
information provided in the ED \\
Bachelor degree & $230.2(293)$ \\
Master degree and higher & $243.87(41)$ \\
Diploma & $262.24(43)$ \\
Less than high school & $275.02(29)$ \\
High school degree & $288.57(156)$ \\
The satisfaction score with the relationship \\
with staff and ED routine \\
Master degree and higher & $224.07(41)$ \\
Bachelor & $229.37(293)$ \\
Diploma & $269.65(43)$ \\
High school degree & $284.33(159)$ \\
Less than high school & $321.64(29)$ \\
Total satisfaction score & \\
Bachelor degree & $226.63(293)$ \\
Master and higher & $232.67(41)$ \\
Diploma & $270.98(43)$ \\
High school degree & $291.33(156)$ \\
Less than high school & $292.55(29)$ \\
\hline
\end{tabular}

TABLE IV

THE MEAN SCORE OF THE DIFFERENT SATISFACTION COMPONENTSIN RELATION TO WHETHER OR NOT THE PATIENT IMPROVED DURING THEIR ED STAY.

\begin{tabular}{lc}
\hline Improvement of health during the ED stay & Mean (n) \\
The satisfaction score with the clarity of information pro- \\
vided in the ED \\
No & $175.17(149)$ \\
Yes & $247.91(199)$ \\
Yes a lot & $290.42(123)$ \\
The satisfaction score with the relationship with staff and \\
ED routine \\
No \\
Yes \\
Yes a lot & $150.39(149)$ \\
Total satisfaction score & $260.54(199)$ \\
No & $300(123)$ \\
Yes & $145.42(149)$ \\
Yes a lot & $256.09(199)$ \\
\end{tabular}

TABLE V

THE DIFFERENT SATISFACTION COMPONENTSIN RELATION TO THE METHOD OF DISCHARGE INSTRUCTIONS PREFERRED BY THE PARTICIPANTS.

\begin{tabular}{lr}
\hline $\begin{array}{l}\text { Method of discharge instructions } \\
\text { The satisfaction score with the clarity of infor- } \\
\text { mation provided in the ED }\end{array}$ \\
$\begin{array}{l}\text { Verbal and written } \\
\text { Written }\end{array}$ \\
$\begin{array}{l}\text { Verbal alone } \\
\text { The satisfaction score with }\end{array}$ & $232.46(147)$ \\
with staff and ED routine & $268.56(263)$ \\
the relationship \\
Verbal and written & \\
Written & $270.68(263)$ \\
Verbal alone & $235.5(147)$ \\
Total satisfaction score & $244.96(56)$ \\
Verbal and written & \\
Written & $275.46(263)$ \\
Verbal alone & $226.09(147)$ \\
\hline
\end{tabular}


[12] U. Hwang, S. N. Hastings, and K. Ramos, "Improving Emergency Department Discharge Care with Telephone Follow-Up. Does It Connect?" Journal of the American Geriatrics Society, vol. 66, no. 3, pp. 436-438, 2018. [Online]. Available: 10.1111/jgs.15218; https: //dx.doi.org/10.1111/jgs.15218

[13] K. J. Biese, J. Busby-Whitehead, J. Cai, S. C. Stearns, E. Roberts, P. Mihas, D. Emmett, Q. Zhou, F. Farmer, and J. S. Kizer, "Telephone Follow-Up for Older Adults Discharged to Home from the Emergency Department: A Pragmatic Randomized Controlled Trial," Journal of the American Geriatrics Society, vol. 66, no. 3, pp. 452-458, 2018. [Online]. Available: 10.1111/jgs.15142;https://dx.doi.org/10.1111/jgs.15142 